\title{
Braking Method of Electric Vehicle Based on Direct Drive Electro- Hydraulic Brake Unit
}

\author{
Xiaoxiang Gong, Siqing Chang*, Lichen Jiang and Xiaopan Li
}

School of Mechanical Engineering, Nanjing University of Science \& Technology, China

\begin{abstract}
For the characteristics of full electric propulsion, a novel kind of brake-by-wire unit is designed for electric vehicle to improve braking performance. A comprehensive brake-by-wire system including this unit is set up after its structure and principle are introduced. Then, a multi-layer fuzzy controller is proposed to regulate decelerate and wheel slip rate, and an optimal regenerative strategy is proposed to recover braking energy. At last, the experiment of brake unit is completed to verify that this novel unit is technologically feasible, and an electric vehicle co-simulation model based on MATLAB/Simulink and AMESim is established to prove that this novel unit is able to significantly improve braking performance of electric vehicle. The simulation result shows braking distance and time are shorten by $12.19 \%$ and $15.54 \%$ respectively compared with conventional ABS system in the same braking condition, and the recovery efficiencies in light and heavy braking are $53 \%$ and $28 \%$ respectively.
\end{abstract}

Keywords: Direct drive electro-hydraulic brake unit, electric vehicle, electromagnetic linear actuator, fuzzy system, regenerative, slip rate.

\section{INTRODUCTION}

The brake system continues to develop because of pursuing of braking safety by human beings, resulting in a number of components integrated into hydraulic brake system, such as anti-lock braking system (ABS), traction control system (TCS) and electronic stability program (ESP) [1]. Although braking performance is typically improved, hydraulic brake system is more complex and still unable to regulate braking force independently and accurately [2]. Additionally, electric vehicle achieves great successes in recent years and becomes the most prospective technologies in automotive industry. However, hydraulic brake system is not matched well with regenerative brake system which is one of the most important advantages in electric vehicle. Thus, it is urgent to design and develop a new kind of brake system for electric vehicle [3].

Brake-by-wire (BBW) such as electronic mechanical brake (EMB) and electronic wedge brake (EWB) are not only able to improve braking performance, but also able to match well with regenerative system so that braking energy can be recovered as much as possible, therefore, it is a huge breakthrough in vehicle industry since the application of ABS system. BBW technology is still imperfect at present, so researchers are working to improve it. Chris Line and Chris Manzie introduced an upgraded PI controller using friction compensation and linearization to improve the performance of EMB [4]. A robust sliding mode controller using a simplified EWB model was designed by Kwangin Han and Myoungjune Kim to upgrade EWB performance [5].

*Address correspondence to this author at the School of Mechanical Engineering, Nanjing University of Science \& Technology, China; Tel: +86 -02584315451; E-mail: changsq@mail.njust.edu.cn
However, EMB and EWB have natural disadvantage because of their structural characteristics. Torque must be enlarged by gear mechanism at first and then be converted into force by ball-screw mechanism in EMB; torque must be converted into force by ball-screw mechanism at first and then be enlarged by wedge mechanism in EWB, because both EMB and EWB are driven by conventional rotary motor $[6,7]$. Therefore, the structures of EMB and EWB are complex and the regulation of braking force is difficult because both motion conversion mechanism and force amplification mechanism are necessary in EMB and EWB.

In order to effectively deal with complex structure in EMB and EWB, a novel kind of BBW unit which is called as direct-drive electro-hydraulic brake (DDEHB) unit and based on electro-magnetic linear actuator (EMLA) is presented in this article. The structure and brake principle are introduced in detail in section 2 as well as the composition of comprehensive brake-by-wire system in electric vehicle. Then, a slip rate controller and a braking force distribution strategy using multi-fuzzy system are designed to regulate braking process and recover braking energy in section 3 . Finally, an experiment is completed to prove that DDEHB is technological feasible, and an electric vehicle co-simulation model based on MATLAB/Simulink and AMESim is established to prove that DDEHB is able to improve the braking performance significantly and to recover braking energy as much as possible in section 4.

\section{PRICIPLE OF DDEHB SYSTEM}

\subsection{Structure of DDEHB}

DDEHB is an independent brake unit which utilities EMLA to convert electrical energy into electro- magnetic force. Then, the force is amplified by unequal diameter 
hydraulic cylinders (UDHC) and forced on brake disc, the structure of DDEHBis shown in Fig. (1) [8].

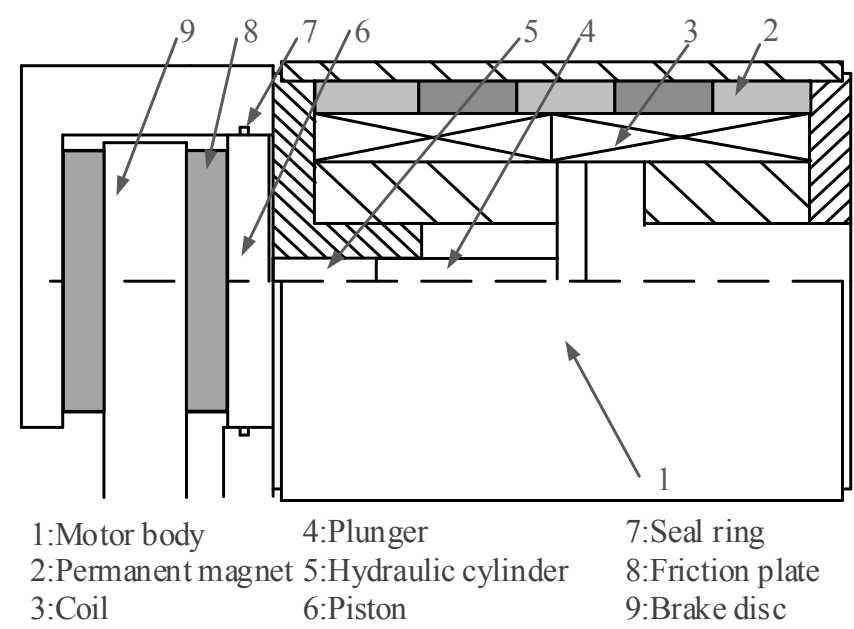

Fig. (1). Structure of DDEHB unit.

In Fig. (1) is EMLA body, permanent magnets 2 are pasted on its inner surface. The coil 3 in magnetic field moves along axis by electromagnetic force when it is energized. The plunger 4 is connected with coil by a pin and moves together with coil. The oil in cylinder 5 is compressed when plunger moves left. The piston 6 is driven to eliminate brake clearance by compressed oil and presses brake disc to slow down wheel speed. As mentioned previously, EMLA converts electricity into electromagnetic force which is enlarged by UDHC and forced on brake disc directly to reduce wheel speed, therefore, the structure DDEHB is simpler than EMB and EWB because it is unnecessary to have conversion mechanisms such as gear mechanism [9$11]$.

\subsection{Model of DDEHB}

EMLA converts electrical energy into electromagnetic force and provides original force for brake unit, its equivalent circuit model is shown in Fig. (2).

The closed voltage is zero according to voltage law of Kirchhoff.

$U_{e}=E_{e}+R_{e} i_{e}+L_{e} i_{e}$

where, $U_{e}$ is the battery voltage, $R_{e}$ is the resistance of coil, $i_{e}$ is the current, $L_{e}$ is the inductance of coil and $E_{e}$ is the counter electromotive force of coil which is calculated as:

$E_{e}=B_{e} l_{e} N_{e} \cdot v_{e}$

where, $B_{e}$ is the magnetic induction, $l_{e}$ is the lap length of coil, $N_{e}$ is the number of turns and $v_{e}$ is the coil velocity.

The coil is driven by electromagnetic force when coil is energized in magnetic field, the force direction is determined by Faraday's left hand rule and its magnitude is calculated as equation (3):

$F_{e}=B_{e} l_{e} N_{e} \cdot i_{e}$

where, $F_{e}$ is the electromagnetic force.

The electromagnetic force generated by EMLA is too small to provide braking force directly, so a UDHC is used to amplify the force. According to literature [12], the model of UDHC is described as equation (4) - (6).

$F_{e}=m_{e} \dot{v}_{e}+C v_{e}+p S_{l}$

$S_{l} \dot{x}_{l}=S_{i} \dot{x}_{i}+10^{3} \frac{S_{i} x_{i}+V_{0}}{K_{c}} \frac{d\left(p-p_{s}\right)}{d t}$

$p_{s}=\frac{F_{s}}{s_{i}}=\frac{K_{o t} \cdot x_{i}}{s_{i}}$

where, $m_{e}$ is the total mass of coil and plunger, $C$ is the damping factor of coil, $S_{l}$ is the cross-area of plunger, $S_{i}$ is the cross-area of piston, $x_{l}$ is the displacement of plunger, $x_{i}$ is the displacement of piston, $K_{c}$ is the equivalent distortion modulus of oil, $V_{0}$ is the initial volume of cylinder, $p$ is the pressure of oil, $F_{s}$ is the equivalent pre-force of cylinder, $p_{s}$ is the equivalent pre-pressure of cylinder, $k_{o t}$ is the stiffness of sealing ring.

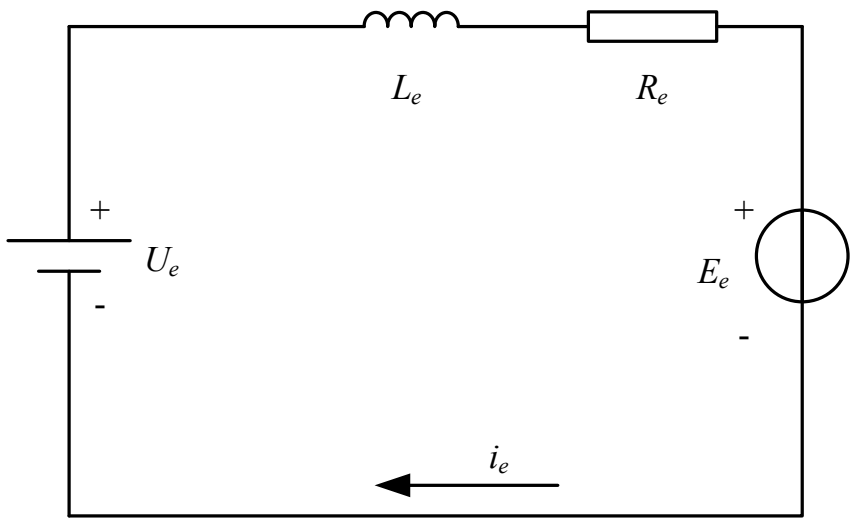

Fig. (2). Equivalent circuit model of EMLA.

The clamping force applied by piston is described as equation (7) after oil pressureis calculated.

$F_{d}=p S_{i}-K_{o t} x_{\text {imax }}$

\subsection{DDEHB System in Electric Vehicle}

EMLA regulates electromagnetic force by adjusting current. Therefore, DDEHB is able to flexibly regulate braking force and has many advantages in electric vehicle.

Electric vehicle battery supplies electric energy to DDEHB directly, it is unnecessary to convert electric energy to high-pressure hydraulic using master cylinder. Not only energy supply of DDEHB is ensured, but also energy conversion loss and transmission loss are avoided.

DDEHB is able to regulate wheels braking force independently, it is easier to regulate braking process than ABS and ESP system.

DDEHB avoids distribution restriction of braking force between axles completely. It is able to match well with regenerative system according to motor capacity and braking condition, thus, the kinetic energy in braking can be recovered as much as possible.

Four DDEHB units combined with sensors, battery, drivers and controllers compose a comprehensive brake-bywire system which is shown as in Fig. (3). 


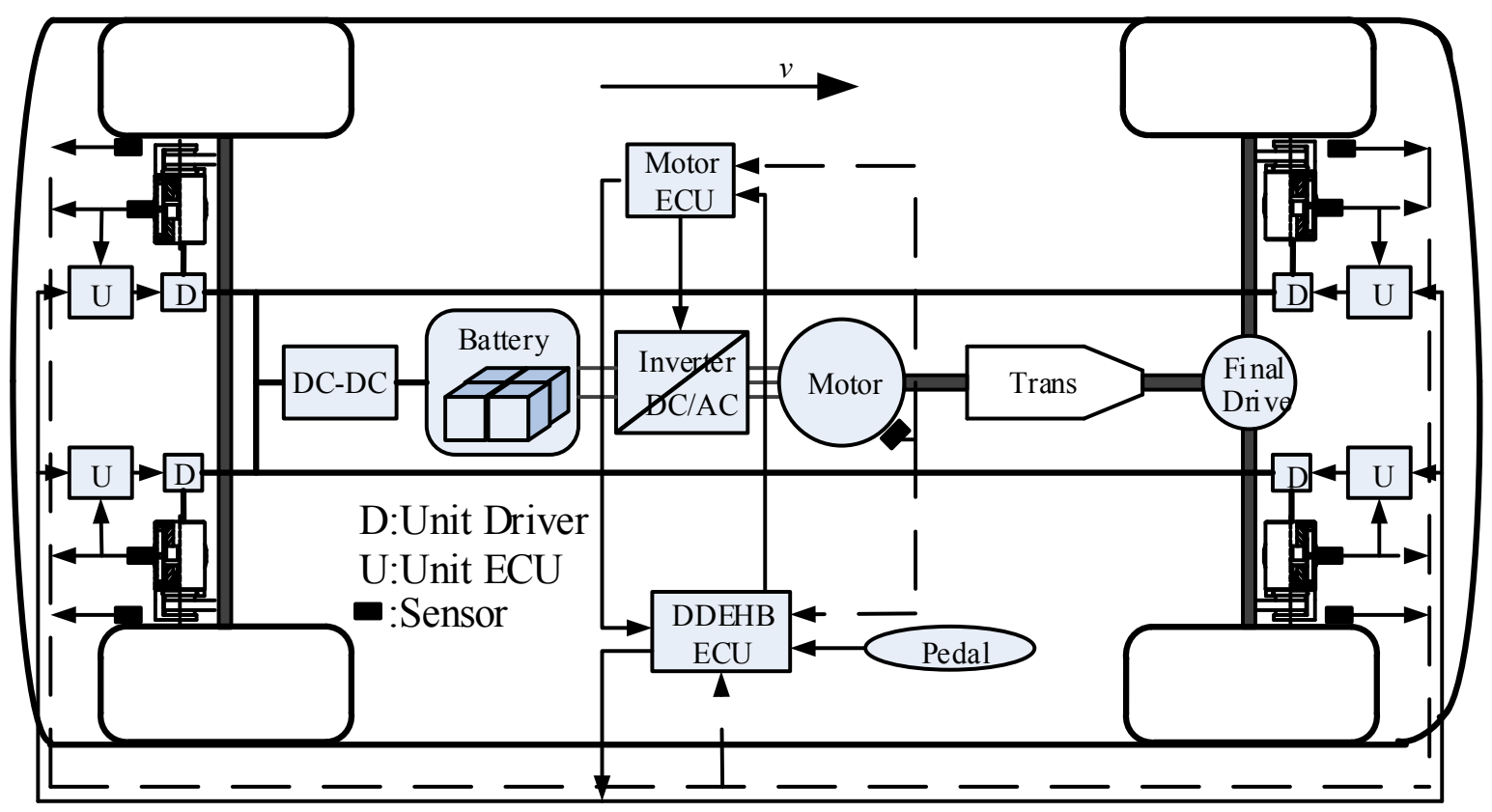

Fig. (3). DDEHB system in electric vehicle.

ECU identifies driver's intention at first according to signal of electronic pedal, meanwhile identifies vehicle condition based on velocity, speed and other signals. The brake force targets are transmitted to unit controllers and motor controller after various signals are handled by ECU. Afterwards, the wheels are controlled to brake independently by DDEHB and motor controller [13]. At last, braking force, velocity, wheels speed and other signals are sent to ECU to form closed-loop controller and to ensure well braking performance [14].

\section{BRAKING METHOD OF ELECTRIC VEHICLE}

The wheel is to be locked if braking force is too strong on poor road condition, resulting in rapidly declining of longitudinal and lateral adhesion coefficient which is show in Fig. (4). Therefore, it is necessary to adjust appropriate braking force according to road condition, otherwise accident would happen in emergency braking.

ABS maintains slip ration in an acceptable range to prevent wheel from locking. However DDEHB is able to maintain slip ratio on its optimum value $\left(s_{\text {opt }}\right)$ because braking force regulates precisely and rapidly by changing coil current, so the braking performance is able to be significantly improved.

\subsection{Fuzzy Control System}

It is difficult to establish vehicle braking model accurately [15], so it is impossible to design a controller using precise model to regulated braking deceleration and wheel slip ratio at the same time. Fortunately, fuzzy system is able to achieve good performance without accurate model, so a fuzzy controller is designed to regular braking process and to recover braking energy.

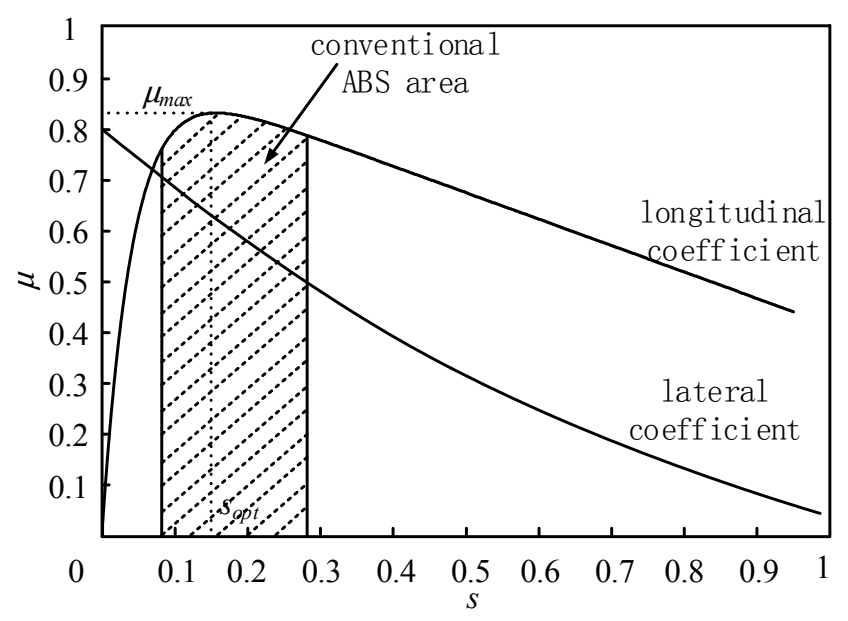

Fig. (4). Relation of coefficient and slip rate.

If three inputs $\Delta s, d s / d t, \Delta F(a)$ are defined for fuzzy controller and every input is mapped to seven fuzzy subsets, the number of fuzzy rules is up to 343. It is difficult and cumbersome to prepare so much rules. Fortunately, Threi has proved that multi-layer fuzzy system as shown in Fig. (5) can effectively reduce rules and ensure good control performance at the same time, in which only 98 rules are necessary [16].

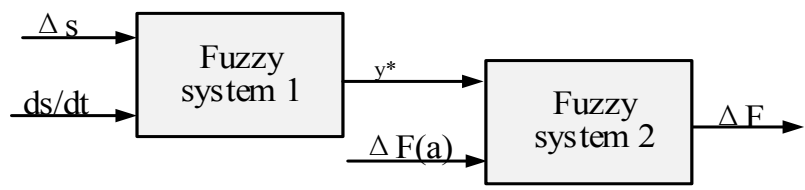

Fig. (5). Multi-fuzzy system.

\subsubsection{First Fuzzy System}

The inputs of fuzzy system 1 in Fig. (5) are $\Delta s$ and $d s / d t$ which are calculated as equation (8) and (9) respectively. 
$\Delta \mathrm{s}=\mathrm{s}-\mathrm{s}_{\text {opt }}$

$\frac{d s}{d t}=\frac{d(\Delta s)}{d t}$

The output $y^{*}$ is increment force which keeps slip rate on its ideal value. The optimum slip ratio is less than 0.3 in normal condition, thus the domain of $\Delta s$ is defined as $U_{\Delta s}=[-$ $0.3,1]$; and the domain of $d s / d t$ is defined as $U_{d s / d t}=[-10,10]$ according to experiences. Then $\Delta s, d s / d t$ and $y^{*}$ are mapped to seven fuzzy subsets shown in Fig. (6) using triangular fuzzier. According to if-then theory, the control rules are shown in Table $\mathbf{1}$, and the corresponding control surface is shown in Fig. (7).
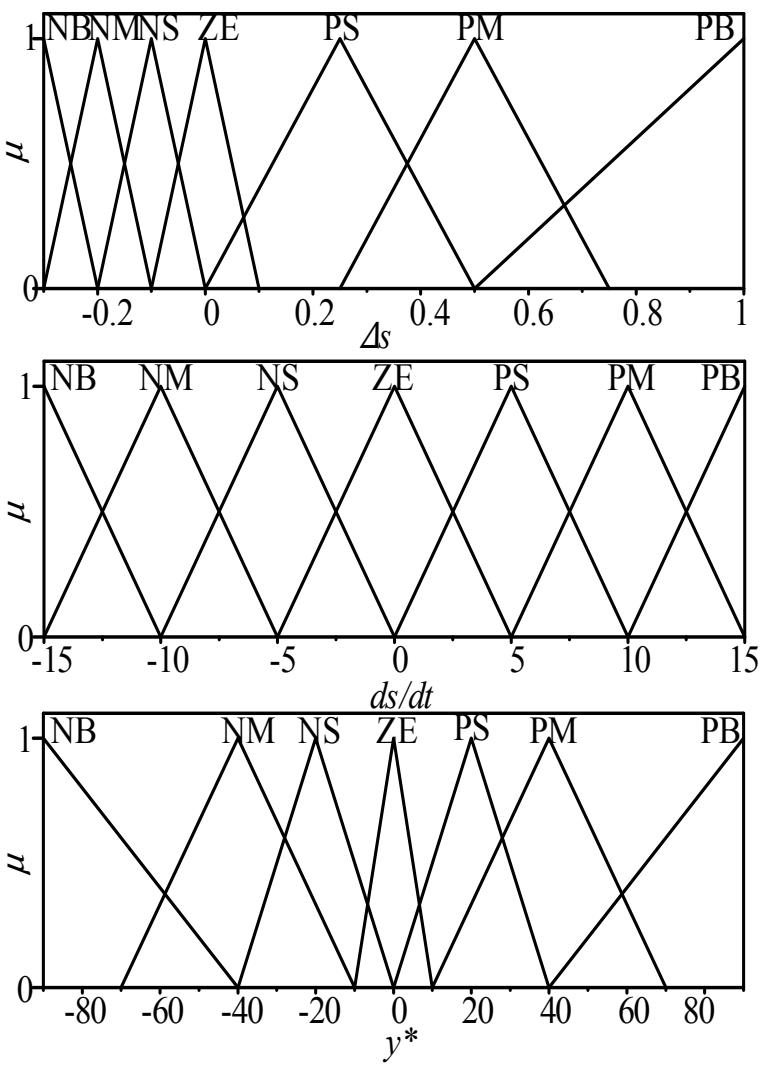

Fig. (6). Fuzzier of first-layer.

Table 1. Control rules of first fuzzy system.

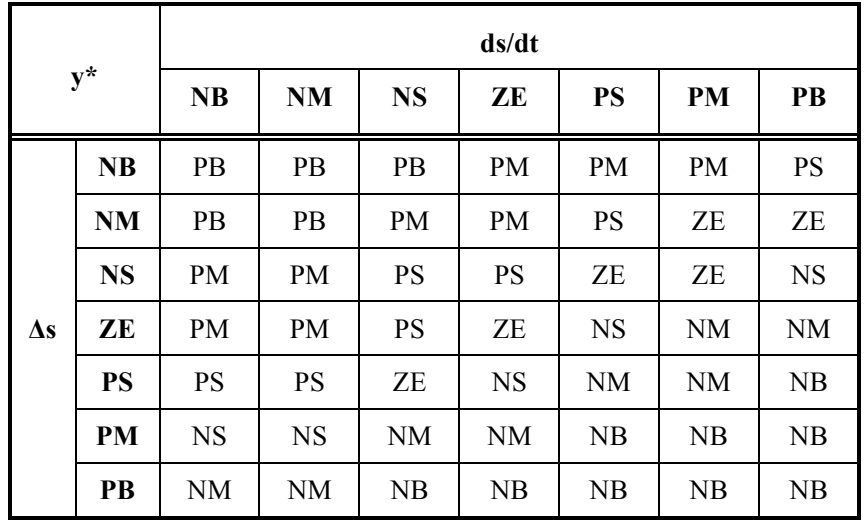

\subsubsection{Second Fuzzy System}

The output $y^{*}$ of system 1 keeps slip rate on its ideal value, it is necessary to reduce braking distance and time in emergency braking. However, the actual decelerate exceeds its target without doubt if slip rate is always kept on its idea value while under light or medium braking. Therefore, fuzzy system 2 is further designed to regulate decelerate. The inputs of system 2 are $y^{*}$ and $\Delta F(a)$, where $\Delta F(a)$ is output of increment PID deceleration controller and is calculated as equation (10)-(12).

$$
\begin{aligned}
e(k)= & a_{\text {opt }}(k)-a_{\text {real }}(k) \\
\Delta u(k)= & k_{p}[e(k)-e(k-1)]+k_{i} e(k)+ \\
& k_{d}[e(k)-2 e(k-1)+e(k-2)] \\
u(k)= & u(k-1)+\Delta u(k)
\end{aligned}
$$

where $k$ is sample number; $a_{\text {opt }}$ and $a_{\text {real }}$ are target and actual deceleration; $k_{p}, k_{i}$ and $k_{d}$ are proportional, integral and differential coefficient.

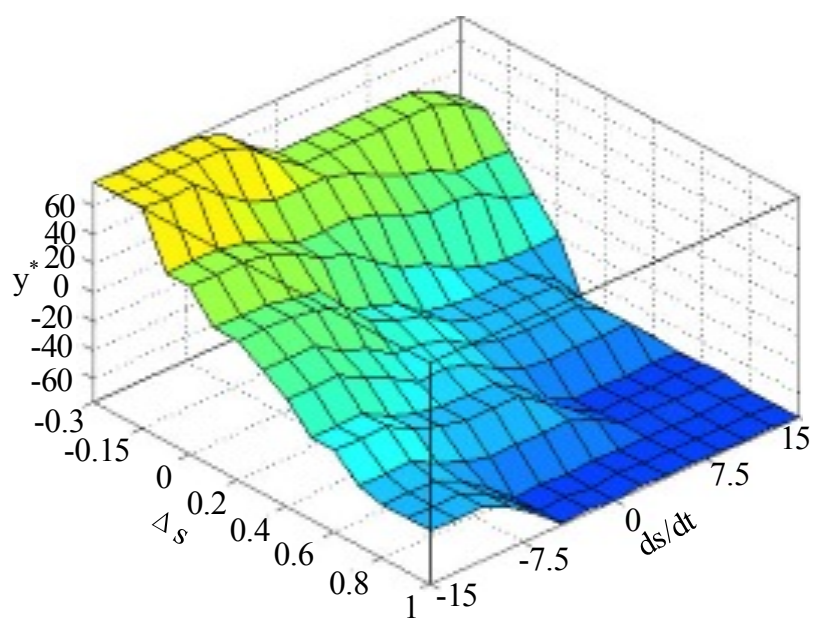

Fig. (7). First fuzzy controller.
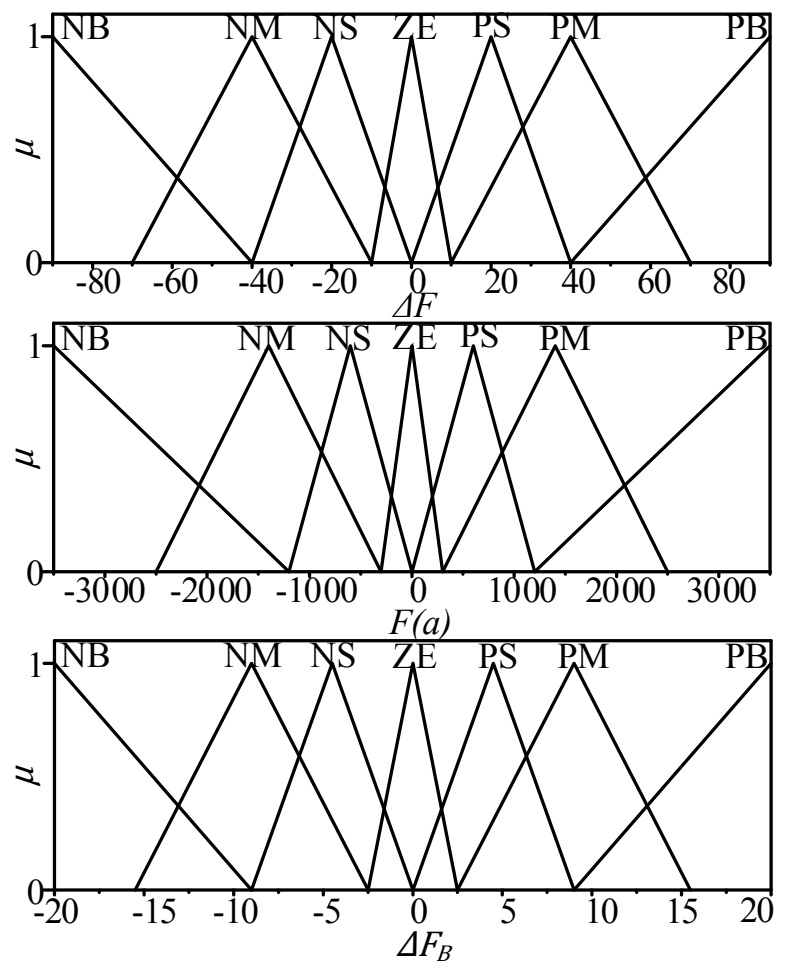

Fig. (8). Fuzzier of second-layer. 
Table 2. Control rules of second fuzzy system.

\begin{tabular}{|c|c|c|c|c|c|c|c|c|}
\hline \multirow{2}{*}{\multicolumn{2}{|c|}{$\Delta \mathbf{F}$}} & \multicolumn{7}{|c|}{$\mathbf{y}^{*}$} \\
\cline { 2 - 8 } \multicolumn{2}{|c|}{} & NB & NM & NS & ZE & PS & PM & PB \\
\hline \hline \multirow{7}{*}{$\Delta \mathbf{F ( a )}$} & NB & NB & NM & NS & ZE & PS & PM & PB \\
\cline { 2 - 9 } & NM & NB & NM & NS & ZE & PS & PM & PM \\
\cline { 2 - 9 } & NS & NB & NM & NS & ZE & PS & PS & PS \\
\cline { 2 - 9 } & ZE & NB & NM & NS & ZE & ZE & ZE & ZE \\
\cline { 2 - 9 } & PS & NB & NM & NS & NS & NS & NS & NS \\
\cline { 2 - 9 } & PM & NB & NM & NM & NM & NM & NM & NM \\
\cline { 2 - 9 } & PB & NB & NB & NB & NB & NB & NB & NB \\
\hline
\end{tabular}

The fuzzy system 2 was designed as Table $\mathbf{2}$, Figs. $(\mathbf{8}, \mathbf{9})$ using same method. Its output $\Delta F$ is increment braking force, thus, the final demand of braking force on every wheel is calculated as equation (13).

$F_{b}(n)=F_{b}(n-1)+\Delta F$

The output $F_{b}(n)$ is not only able to keep slip rate on its ideal value in emergency braking, but also able to trackdeceleration target in light and medium braking.

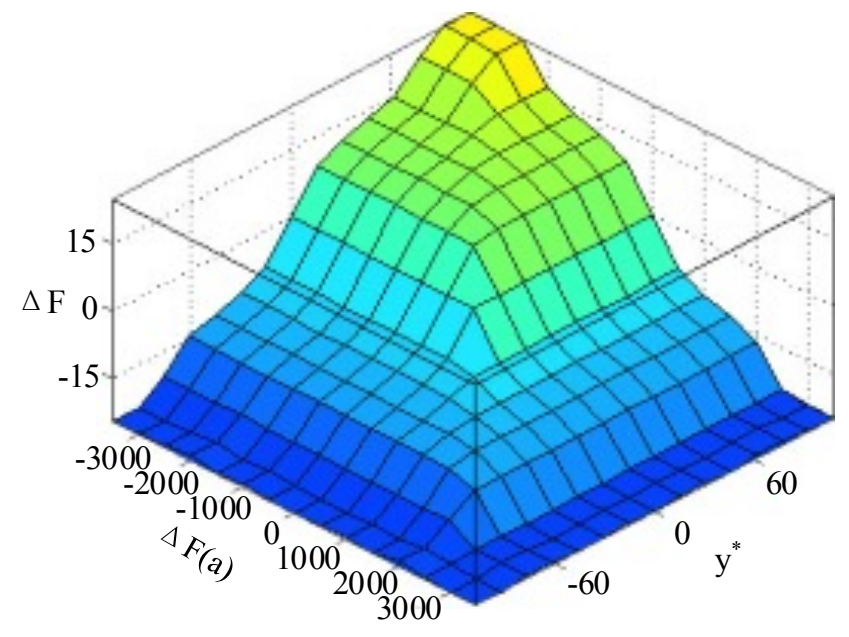

Fig. (9). Second fuzzy controller.

\subsection{Distribution of Regenerative and Friction Force on Driveshaft}

In order to recover braking energy, braking force on drive axle should be assigned again between regenerative system and DDEHB unit. As mentioned previously, DDEHB is able to regulate braking force of each wheel flexibly, braking force distribution do not be restricted as hydraulic brake system. Thereby, the braking force on non-driveshaft wheels are friction braking force provided by DDEHB unit and their magnitude are the same as $F_{b}(n)$. But braking force on driveshaft wheels are distributed on regenerative system and DDEHB unit again according to motor capacity and braking force demand $F_{b}(n)$ on driveshaft wheels, they are distributed after comparing total force demand on driveshaft wheels with maximum regenerative force that motor is able to provide.
The regenerative torque (equivalent to regenerative force) is affected by many factors, such as velocity, wheel speed, battery voltage and SOC. According to literature [17], the maximum regenerative torque $T_{\max }$ is determined by equation (14)-(16).

$T_{m}=\left\{\begin{array}{cc}T_{n} & n \leq n_{n} \\ 9550 \times P_{n} / n_{n} & n>n_{n}\end{array}\right.$

$\Pi W=W_{1}(v) W_{2}(S O C) W_{3}(U) W_{1}($ Fault $)$

$T_{\text {max }}=T_{m} \prod W$

where, $T_{n}$ is rated torque, $P_{n}$ is rated power, $n_{n}$ is rated speed, $\mathrm{T}_{\mathrm{m}}$ is theoretical maximum torque, $W_{l}(v), W_{2}(S O C), W_{3}(U)$ and $W_{4}$ (Fault) are functions of speed, SOC, voltage and system status respectively, the value of these function is between 0 to 1 .

Because drive motor responses more slowly than DDEHB, a cascade braking force distribution method shown as Fig. (10) is designed to precisely regulate braking force on driveshaft. The demand braking force on driveshaft is compared with maximum regenerative force at first, the smaller is considered as the target of regenerative force (equivalent to regenerative torque). Then, motor is controlled to provide regenerative force by motor controller and the actual regenerative force is feedback to both motor controller and DDEHB controller. DDEHB supplies friction force to meet the demand force if regenerative force is insufficient, otherwise DDEHB does not provide friction braking force, the distribution strategy is described as equation (17)-(20).

$F_{\text {total }}=F_{1}+F_{2}$

$F_{\text {reg_max }}=\frac{T_{\max i_{0} i_{g}}}{r_{\text {disc }}}$

$F_{\text {reg_target }}=\min \left(F_{\text {total }}, F_{\text {reg_max }}\right)$

$F_{1,2 \_ \text {target }}=\left\{\begin{array}{cl}0 & \text { if } F_{\text {total }} \leq F_{\text {reg_max }} \\ F_{1,2}-0.5 F_{\text {reg_real }} & \text { if } F_{\text {total }}>F_{\text {reg_max }}\end{array}\right.$

where $F_{1}, F_{2}$ are braking force demand on driveshaft wheels and they are calculated as equation (13), $F_{\text {total }}$ are total braking force demand on driveshaft, $i_{0}$ and $i_{g}$ are transmission ration of main reducer and transmission respectively, $r_{\text {disc }}$ is brake disc radius, $F_{\text {reg_max }}$ is maximum regenerative braking force that drive motor is able to provide, $F_{\text {reg_target }}$ is target of regenerative braking force, $F_{1}$ target and $F_{2 \_ \text {target }}$ are target of friction braking forceon driveshaft wheels provided by DDEHB unit.

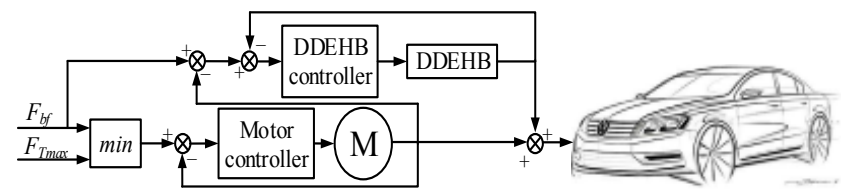

Fig. (10). Torque distribution method on drive shaft.

Therefore, motor provides all braking force for driveshaft if requirement is small; and it is also priority to provide regenerative force if requirement is high. So braking energy is able to be recovered as much as possible.

The constant of motor is always large, brings about that the wheel is probable to be locked as a result of large 
overshoot of motor toque [18]. For this reason, a transition process is introduced for motor torque, which is effective to prevent the motor from overshoot. The transition process is described as equation (21) and (22).

$\dot{T}_{1}=T_{2}$

$\dot{T}_{2}=\operatorname{fhan}\left(T_{1}-T_{\text {target }}, T_{2}, r, h\right)$

where, $T_{\text {target }}$ is target torque; $T_{1}$ is transient torque of $T_{\text {target }}, T_{2}$ is differential of transient torque, $r$ is tracking velocity factor, $h$ tracking precision factor and $\operatorname{fhan}\left(x_{1}, x_{2}, r, h\right)$ is nonlinear function described in [19].

After braking force is distributed on regenerative braking system and DDEHB unit, DDEHB and motor provide proper friction force and regenerative force to every wheels according to their target value. Both DDEHB and motor controllers use incremental PID method which is same as equation (10)-(12), so they are not discussed in detail at here.

\section{EXPERIMENT AND SIMULATION}

\subsection{Experiment and Simulation of DDEHB}

In order to verify, DDEHB is feasible, a prototype modified form one type of hydraulic brake is completed, and a co-simulation model constructed by Simulink and AMESim is also finished at the same time, which are shown as Figs. (11-13), where Simulink is used to construct EMLA model and AMESim is used to construct UDHC and clipper models. The DDEHB and EMLA parameters are shown in Tables 3 and $\mathbf{4}$. The results of experiment and simulation are shown in Figs. $(\mathbf{1 4}, \mathbf{1 5})$.

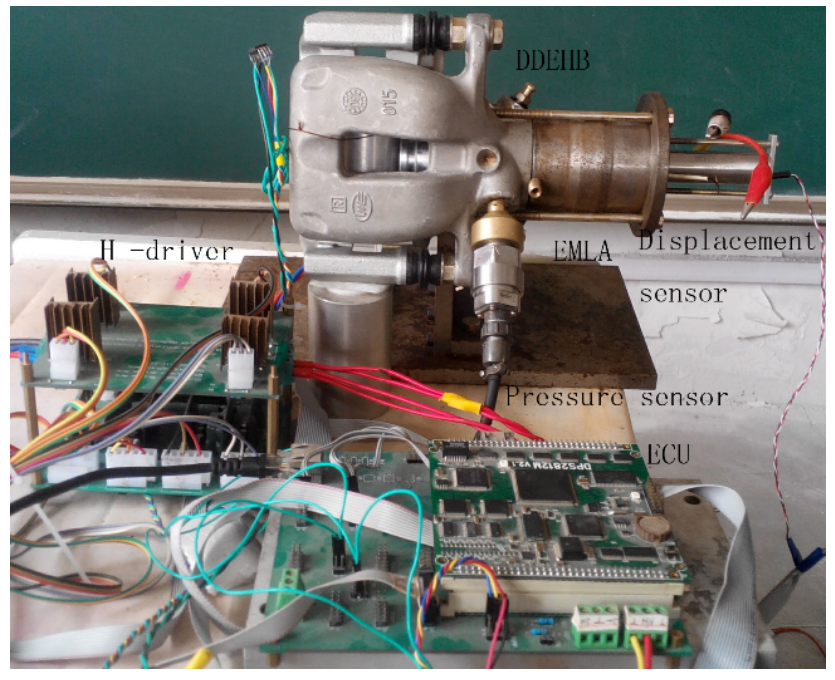

Fig. (11). Prototype of DDEHB.

It is not easy to measure clamping force directly by using large range force sensor due to the limited space of clipper, therefore a hydraulic pressure sensor is used to measure the pressure in UDHC and thus to measure the clamping force indirectly. The response results show that the response time of $5 \mathrm{MPa}$ is about $12 \mathrm{~ms}$, it indicates that not only the response time of DDEHB is far less than hydraulic brake system with response time of 0.1 seconds [20], but also less than EMB with response time of $63 \mathrm{~ms}$ [21]. According to Kerem Bayard's research, the response time of EHB with 80 bar
Table 3. Parameters of DDEHB.

\begin{tabular}{|c|c|}
\hline Parameter & Value \\
\hline \hline Piston diameter $/ \mathrm{mm}$ & 38 \\
\hline Plunger diameter $/ \mathrm{mm}$ & 6 \\
\hline Max pressure $/ \mathrm{Mpa}$ & 12 \\
\hline Max braking force $/ \mathrm{N}$ & $10343(\mu=0.38)$ \\
\hline Max piston pressure $/ \mathrm{N}$ & 27219 \\
\hline Electromagnetic force $/ \mathrm{N}$ & 339 \\
\hline
\end{tabular}

Table 4. Parameters of EMLA.

\begin{tabular}{|c|c|}
\hline Parameter & Value \\
\hline \hline EMLA diameter $/ \mathrm{mm}$ & 60 \\
\hline EMLA length $/ \mathrm{mm}$ & 70 \\
\hline EMLA voltage $/ \mathrm{V}$ & 24 \\
\hline Coil resistance $/ \Omega$ & 0.7615 \\
\hline Coil inductance $/ \mu \mathrm{H}$ & 279.8 \\
\hline Peak current $/ \mathrm{A}$ & 20 \\
\hline
\end{tabular}

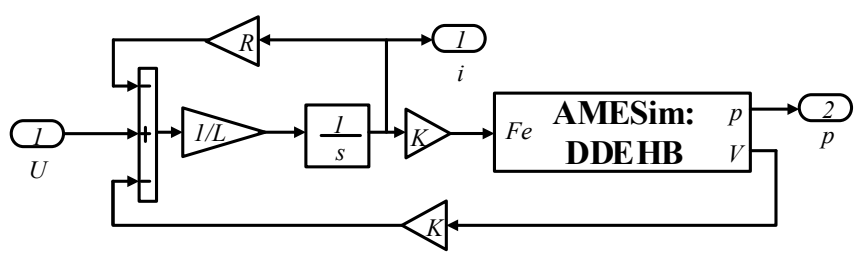

Fig. (12). Model of ELMA.

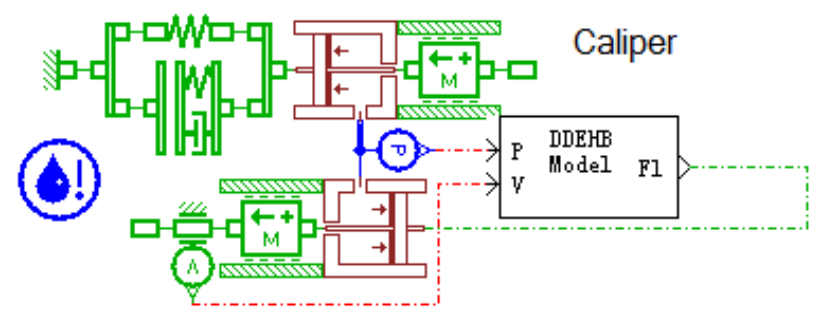

Fig. (13). Model of UDHC and clipper.

pressure in caliper is $50 \mathrm{~ms}$ [22]. It can be supposed that the response of DDEHB is faster than EHB because the oil in UDHC is compressed directly by EMLA while the pressure is still boosted by master cylinder at first and then passed to wheel cylinder by hydraulic pipeline in EHB. On the other hand, the tracking characteristic shows the pressure in UDHC is capable of tracking the target accurately, indicating that pressure can be accurately regulated. Thereby it is possible to accurately control the process of braking and coordinate well with regenerative braking system. Additionally, the uncomfortable feeling is also eliminated because the brake pedal never bounces and the braking performance is improved because of accurately controlled braking force. 


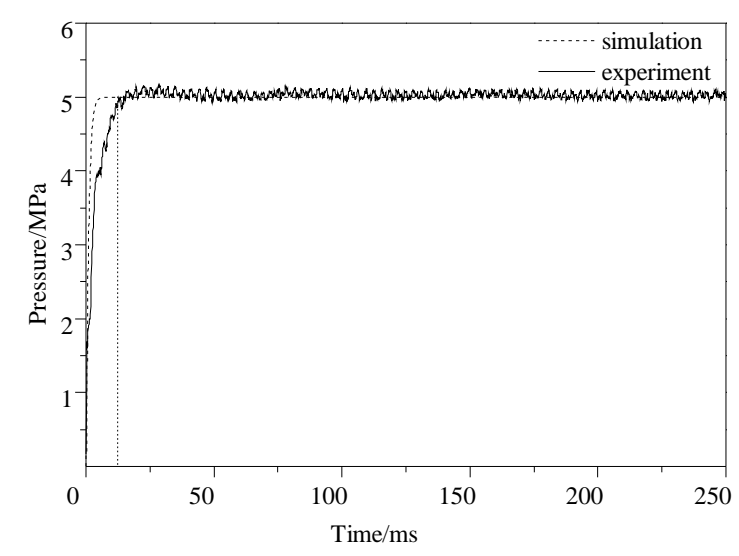

Fig. (14). Response of 5MPa.

\subsection{Simulation of Electric Vehicle}

The simulation and experimental datum indicates that the braking scheme is technically feasible, and there is a great prospect after it is improved and optimized. So acosimulation model was established based on AMESim and MATLAB/Simulink to verify that the braking method introduced in sections 2 and 3 is effective and reliable. MATLAB/Simulink is used to establish controllers including deceleration controller, slip rate controller, road recognition controller, DDEHB controller, motor torque controller and brake force distribution controller as discussed in section 3, which is shown in Fig. (16); AMESim is used to establish electrical and mechanical models for electric vehicle including vehicle model, DDEHB model, motor model and battery model, which is shown as in Fig. (3).

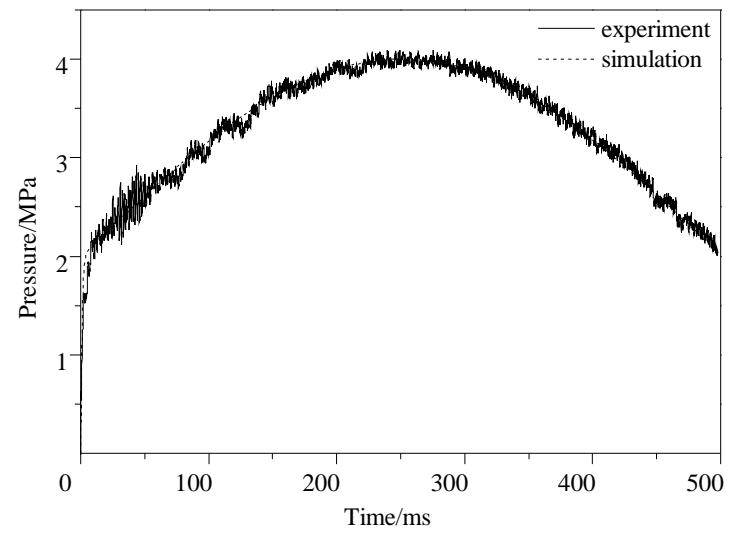

Fig. (15). Track of sinusoidal.

The adhesion coefficient of road is about 0.45 . On the one hand, in order to test the deceleration tracking performance and regenerative performance, the initial velocity and target deceleration are set as $10 \mathrm{~m} / \mathrm{s}$ and $2 \mathrm{~m} / \mathrm{s}^{2}$ respectively in light braking; on the other hand, the initial velocity and target deceleration are set as $25 \mathrm{~m} / \mathrm{s}$ and $6 \mathrm{~m} / \mathrm{s}^{2}$ respectively in high braking in order to test anti-lock braking performance. The main parameters of the electric vehicle are listed in Table $\mathbf{5}$.

The velocity and deceleration shown in Fig. (17) illustrate that braking process is perfect smooth in both braking condition. Because deceleration is small in light braking, the road is capable of providing sufficient friction force to wheel, so the actual deceleration is kept accurately on its target value. But in high braking, because the road is

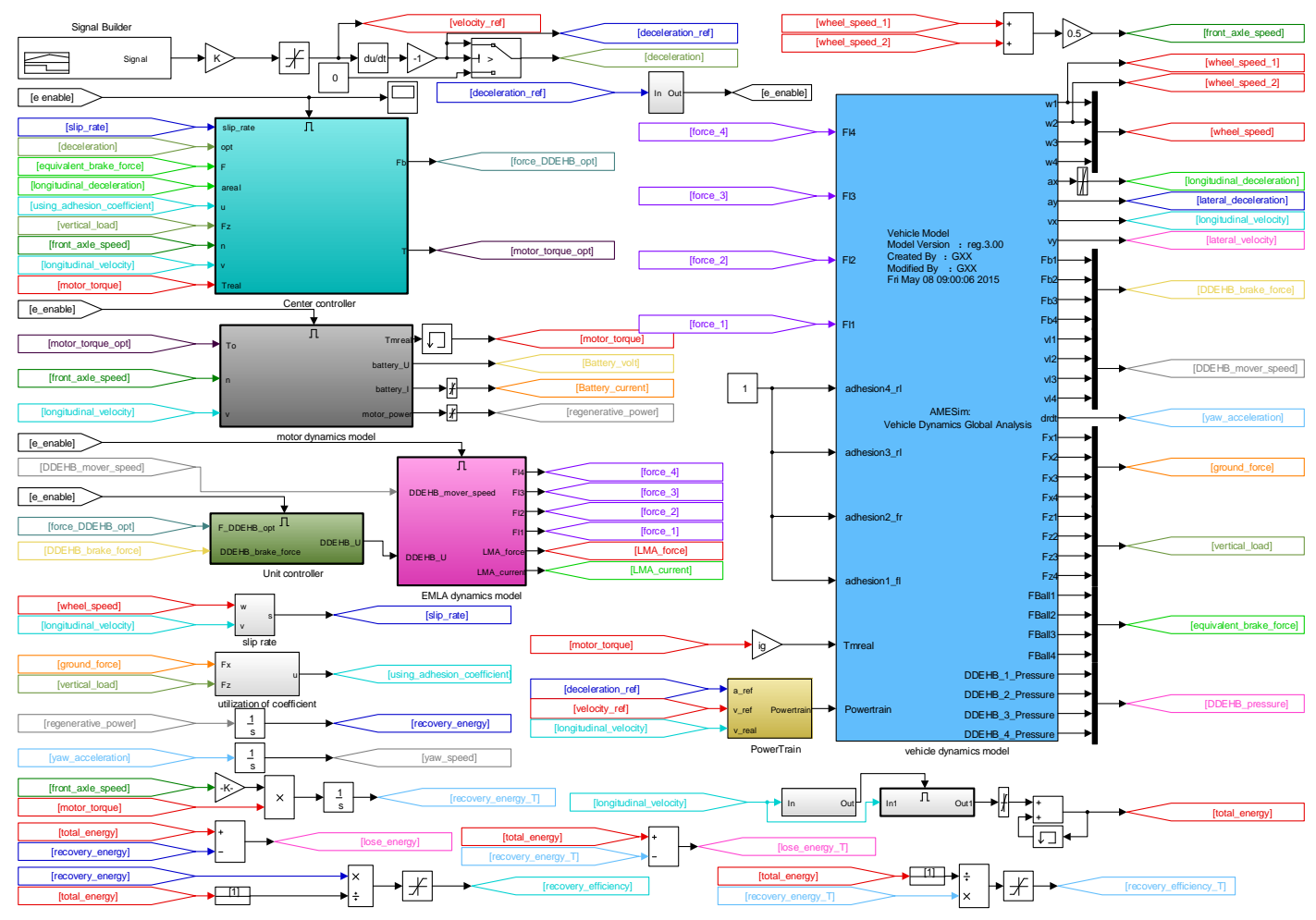

Fig. (16). Control system model of EV. 
Table 5. Simulation parameters.

\begin{tabular}{|c|c|c|}
\hline Parameter & Symbol & Value \\
\hline \hline Resistance of EMLA & $R_{e}(\Omega)$ & 0.76 \\
\hline Inductance of EMLA & $L_{e}(\mu \mathrm{H})$ & 285 \\
\hline Constant of EMLA & $K_{e}$ & 14.2 \\
\hline Diameter of piston & $d_{p i}(\mathrm{~mm})$ & 38 \\
\hline Diameter of plunger & $d_{p l}(\mathrm{~mm})$ & 6 \\
\hline Coefficient of friction block & $\mu$ & 0.38 \\
\hline Mass of vehicle & $M(\mathrm{Kg})$ & 1367 \\
\hline Height of center & $H_{g}(\mathrm{~mm})$ & 375 \\
\hline Wheel base & $l(\mathrm{~mm})$ & 2400 \\
\hline Front wheel base & $l_{f}(\mathrm{~mm})$ & 1056 \\
\hline Rear wheel base & $l_{r}(\mathrm{~mm})$ & 1344 \\
\hline Rated power of motor & $P_{r}(\mathrm{Kw})$ & 60 \\
\hline Rated torque of motor & $T_{r}(\mathrm{~N} . \mathrm{m})$ & 200 \\
\hline Rated speed of motor & $n_{n}(\mathrm{r} / \mathrm{min})$ & 3000 \\
\hline Rated voltage of battery & $U_{r}(\mathrm{~V})$ & 440 \\
\hline Rated current of battery & $I_{r}(\mathrm{~A})$ & 45 \\
\hline
\end{tabular}

not capable of providing sufficient friction force, it is can be seen that the wheels trend to be locked (also indicated in Fig. 18) and the actual deceleration declines quickly at the beginning of braking. Fortunately, the anti-lock program is activated timely, and the control target is converted to optimum slip rate timely instead of target deceleration which can't reach on this road. Therefore, the actual deceleration has been kept at an ideal value.

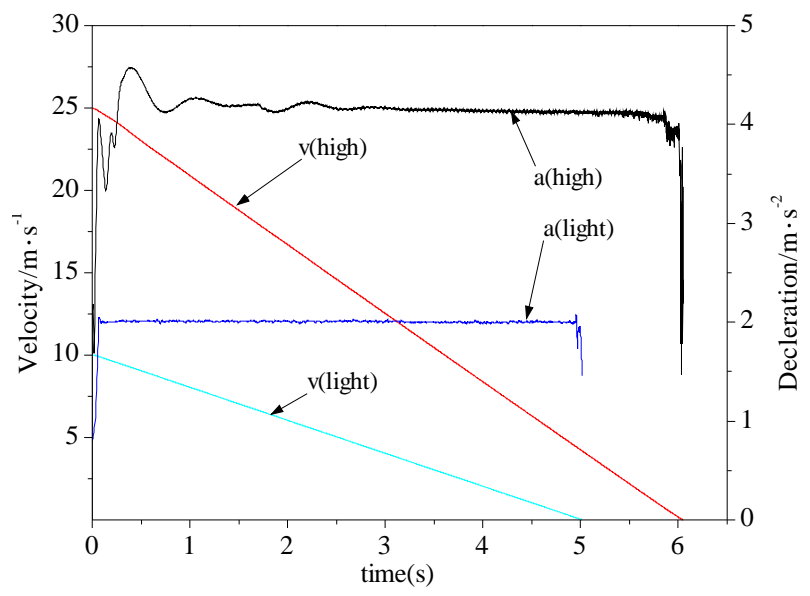

Fig. (17). Velocity and deceleration.

The simulation results show that all of the deceleration, velocity, wheel speed, slip rate and using adhesion coefficient are all smooth in both conditions. Especially in high braking, the wheel speed and slip rate are not as fluctuation as conventional ABS when anti-lock function is activated, so the bounce of brake pedal is effectively avoided and the braking process is more comfort than ABS system. Additionally, the braking force is able to be reasonably applied on front and rear wheels since force can be independently controlled in DDEHB system, thus, the adhesion coefficient between front and rear wheels are almost equal in both braking condition (shown in Fig. 18). It is capable of utilizing the adhesion capacity of road more reasonable and fully, and the actual deceleration is an ideal value that the road is able to sustain in emergency braking, therefore, the braking distance and time can be as short as possible.

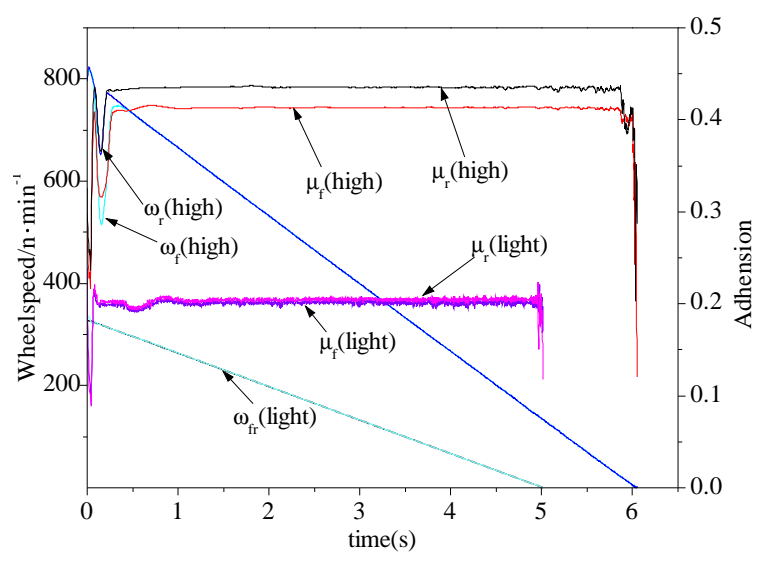

Fig. (18). Wheel speed and adhesion coefficient.

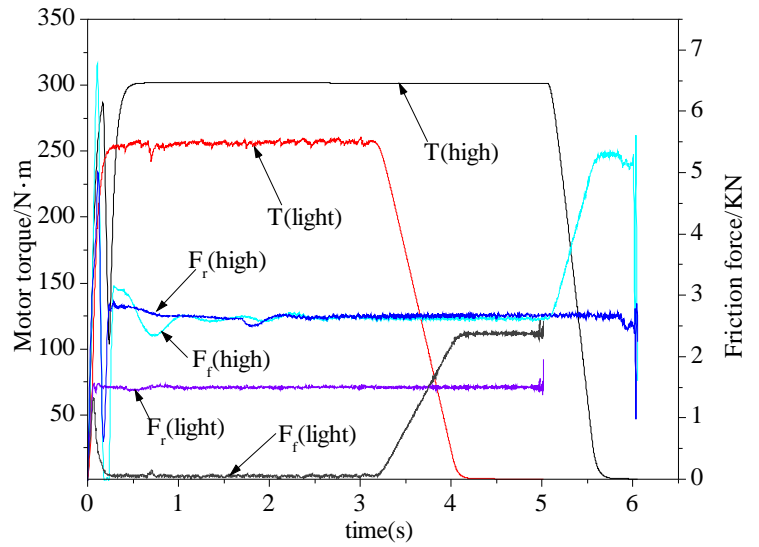

Fig. (19). Regenerative torque and friction force.

Moreover, the braking force on driveshaft (front shaft) is distributed more flexibly on regenerative and DDEHB system according to total force on driveshaft and maximum regenerative force that motor is able to provide which is shown in Fig. (19). If the requirement of force is small, all force on driveshaft is regenerative force and there is on friction force, therefore the friction force on front axle provides by DDEHB in 0-3.2 second in light braking is almost zero because the motor provides all braking force for front wheels. After 3.2 second, the motor regenerative torque declines as the vehicle velocity declines because the velocity is small and the regenerative efficiency decreases rapidly, so it can be seen that the friction force on front wheels increases along with the declining of regenerative torque. But if the requirement of force on front axle is strong, the motor provided regenerative as much as it can be, and the lack of 
force is rapidly compensated by increasing friction force of DDEHB. Therefore it can be seen that the motor provided the maximum regenerative torque in $0-5.3$ second in heavy braking, and the DDEHB also provide some friction force for front wheels. And after 5.3 second, the friction force on front wheels increases along with the declining of regenerative torque as it is in light braking. Finally, it is can be seen from Figs. $(\mathbf{1 9}, \mathbf{2 0})$ that braking force on driveshaft is almost provided by motor in light braking and corresponding recovery efficiency is up to $53 \%$; but the efficiency is only $28 \%$ in heavy braking because the total requirement of force is large, although motor provided regenerative force as much as possible.

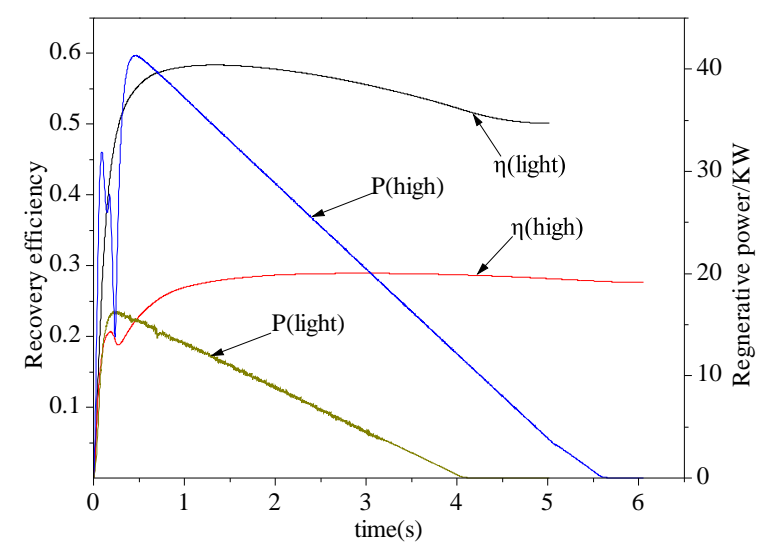

Fig. (20). Recovery efficiency and power.

The braking distance and time of DDEHB and conventional ABS system in the same braking condition with initial velocity of $30 \mathrm{~m} / \mathrm{s}$ are shown in Table 6. The ABS control method is typically logic threshold applied in wide range of conventional vehicle. The pressure in wheel cylinder continues to 'drop-remain-rise-remain' in whole braking process, thus the slip rate is kept on reasonable range (shown in Fig. 4) and the wheel is prevented locking. Hence the pressure in cylinder is not always at the ideal value in ABS, the adhesion capacity of road is not fully used in emergency and high braking. Pressure in DDEHB is able to be accurately controlled on ideal value by adjusting coil current after identifying the road condition, so that the vehicle is able to make full use of adhesion capacity. The simulation results show the braking distance in DDEHB

Table 6. Braking distance and time between DDEHB and conventional ABS system.

\begin{tabular}{|c|c|c|}
\hline Brake System & Braking Distance/ $\boldsymbol{m}$ & Braking Time/s \\
\hline \hline ABS & 123.85 & 8.56 \\
\hline DDEHB & 108.75 & 7.23 \\
\hline Improved & $12.19 \%$ & $15.54 \%$ \\
\hline
\end{tabular}

system is reduced by $12.19 \%$ compared with ABS system, and the braking time is shorten by $15.54 \%$.

\section{CONCLUSION}

DDEHB system with excellent controller and excellent regenerative strategy is able to effectively improve braking performance and recovery efficiency of electric vehicle, the main advantages of DDEHB are:

(1) The braking force is able to be controlled independently and accurately; and the force distribution between front and rear wheels is no longer restricted by hydraulic brake system, so the force is more reasonably acted on wheels. In addition, DDEHB responses rapidly and is able to match well with regenerative system, so the recovery efficiency is significantly improved.

(2) The controller is able to accurately regulate slip rate and deceleration, the vehicle is capable of making full use of adhesion force and the braking distance and time are short as much as possible.

(3) The designed regenerative strategy is able to recover braking energy as much as possible according to the maximum regenerative force of motor and the requirement of force on driveshaft.

\section{CONFLICT OF INTEREST}

The authors confirm that this article content has no conflict of interest.

\section{ACKNOWLEDGEMENTS}

Declared none.

\section{REFERENCES}

[1] M. Jinlai, W. Bofu, and C. Jie, "Comparisons of 4WS and BrakeFAS based on IMC for vehicle stability control", Journal of Mechanical Science and Technology, vol. 25, no. 5, pp. 1265-1277, 2011.

[2] J. Hartley, A. Day, I. Campean, R. G. McLellan, and J. Richmond, "Braking System for a Full Electric Vehicle with Regenerative Braking", In: 2010 SAE Annual Brake Colloquium and Engineering Display, 2010, pp. 2010-01-1680.

[3] Y. Yajuan, Z. Han and Z. Maofei, "A study on the control strategy for maximum energy recovery by regenerative braking in electric vehicle", Automotive Engineering, vol. 2, pp. 105-110, 2013.

[4] C. Line, C. Manzie, and M. C. Good, "Electro-mechanical brake modeling and control: from PI to MPC", IEEE Transactions on Control Systems Technology, vol. 6, no. 3, pp. 446-457, 2008.

[5] K. Han, M. Kim and K. Huh, "Modeling and control of an electronic wedge brake", Proceedings of the Institution of Mechanical Engineers, Part C: Journal of Mechanical Engineering Science, vol. 226, no. 10, pp. 2440-2455, 2012.

[6] D. B. Drennen, E. R. Siler, and J. R. Wag, "Electric Brake Caliper Having a Ball Screw with Integral Gear Carrier”, U.S. Patent No. US20050034936, Delphi Technologies, Troy, 2005.

[7] J. Fox, R. Roberts, C. Baier-Welt, L. M. Ho, and L. Lacraru, "Modeling and control of a single motor electronic wedge brake," In: 2006 SAE International, 2006, pp. 2007-01-0886.

[8] S. Q. Chang, X. X. Gong, and X. P. Li, "Direct Drive ElectroHydraulic Brake Unit for a Brake-by-Wire System", China Patent: 201110332564.1, October 28, 2011.

[9] D. Guan, X. H. Yang, G. Liu, T. Tong, and S. J. Ma, "The Study of Electromechanical Brake Device Based on the Ball Screw", Mechanical Engineering and Green Manufacturing II, vol. 155, no. 109, pp. 509-513, 2012. 
[10] U. Gottwick and M. Kunz, "Electrohydraulic Braking System", U.S. Patent 7770982B2, February 25, 2010.

[11] J. S. Cheon, "Brake by wire system configuration and functions using front EWB (Electric Wedge Brake) and rear EMB (ElectroMechanical Brake) actuators", In: 2010 SAE Annual Brake Colloquium and Engineering Display, 2010, pp. 2010-01-1708.

[12] Z. Y. Li, Z. D. Liu, H. F. Cui, and R. Wang, "Experimental study on change rate model of brake pressure of ABS wheel cylinder", Transaction of the Chinese Society for Agricultural Machinery, vol. 38, no. 9, pp. 6-9, 2007.

[13] B. P. Riddiford, J. B. Hageman, and D. E. Schenk, Brake by Wire System with Separate Controllers and Both Postion and Force Input Sensors, US Patent No. US6390565 B2, Delphi Technologies, Troy, 2002.

[14] F. Canuto, P. Turco, and D. Colombo, "Control development process of the brake-by-wire system", In: ESDA2006: Proceedings of 8th Biennial ASME Conference on Engineering Systems Design and Analysis, 2006, pp. 349-358.

[15] I. Jiro, K. Masatoshi, I. Toshikatsu, and A. Satoshi, "Optimization of DC feeding system for electric cars with regenerative brake", Quarterly Report of RTRI (Railway Technical Research Institute) (Japan), vol. 36, no. 1, pp. 40-47, 1995.
[16] L. X. Wang, A Course in Fuzzy Systems \& Control, China: Tsinghua University Press, 2003.

[17] L. Zhou, Y. G. Luo, D. G. Yang, U. Tsinghua, and K. Li, “A novel brake control strategy for electric vehicles based on slip trial method", In: 2007 ICVES:IEEE International Conference on Vehicular Electronics and Safety, 2007, pp. 225-230.

[18] E. Afjei, O. Hashemipour, and M. Saati, "A new hybrid brushless DC motor/generator without permanent magnet", International Journal of Engineering Transaction B: Application, vol. 20, no. 1, pp. 77-86, 2007.

[19] J. Q. Han, "Auto disturbances rejection control technique", Frontier Science, vol. 1, pp. 24-31, 2007.

[20] Z. S. Yu, Vehicle Theory, $4^{\text {th }}$ ed., China Machine Press, Beijing, China, 2007, pp. 98-99.

[21] S. L. Tan, "Research on Actuator of Electro-mechanical Brake and Hardware in-the-Loop Test Bench for Light Vehicle", PhD thesis, Jilin University, Jilin, China, 2008.

[22] K. Bayar, R. Biasini, S. Onori, Giorgio Rizzoni, "Modelling and control of a brake system for an extended range electric vehicle equipped with axle Motors", International Journal of Vehicle Design, vol. 58, no. 2-4, pp. 399-426, 2012.

(c) Gong et al.; Licensee Bentham Open.

This is an open access article licensed under the terms of the Creative Commons Attribution Non-Commercial License (http://creativecommons.org/licenses/by-nc/3.0/) which permits unrestricted, non-commercial use, distribution and reproduction in any medium, provided the work is properly cited. 